INTERNATIONAL JOURNAL OF RESEARCHES IN BIOSCIENCES, AGRICULTURE AND TECHNOLOGY C VISHWASHANTI MULTIPURPOSE SOCIETY (Global Peace Multipurpose Society) R. No. MH-659/13(N) www.ijrbat.in

\title{
STUDY OF PHOSPHATE SOLUBILIZATION AND CELLULASE DEGRADATION ACTIVITY OF ANTIFUNGAL BACILLUS ISOLATES AGAINST FUSARIUM AND PYTHIUM SPECIES.
}

\author{
B. M. Sandikar \\ Department of Microbiology, Maharashtra Udayagiri College, Udgir- 413517; Dist. Latur (Maharashtra). \\ E-mail balkrishna64@rediffmail.com.
}

\begin{abstract}
:
Among ' 150 ' Bacillus isolates obtained from rhizosphere of healthy crop plants, eight isolates showing potent antifungal activity (percent growth inhibition $>50 \%$ ) against the phytopathogenic Fusarium and Pythium species were selected by dual culture (Co-culture) method, using PDA and PDB. These antifungal isolates were identified on the basis of morphological, cultural and biochemical characters as well as 16S r-RNA gene sequencing as Bacillus thuringiensis184, B. subtilis208, B. thuringiensis211, B. cereus220, B. cereus228, B. subtilis252, B. subtilis 260 and $B$. subtilis 288 and used to prepare biocontrol formulations with dried fecal pellets of sheep and goats. These Bacillus isolates were also studied for phosphate solubilization and cellulose degradation abilities using Pikovskaya (PVK) agar and Carboxyl methyl cellulose (CMC)- Peptone medium, respectively. Among the eight isolates, three isolates i.e. Bacillus subtilis208, B. cereus220 and B. subtilis252 were showed good phosphate solubilization ability whereas only $B$. subtilis 252 showed considerable cellulase activity. We conclude that, application of these three isolates in soil will be significant not only as biological control agents of fungal diseases but also as plant growth promoting rhizobacteria (PGPR) to increase soil fertility, especially with respect to phosphate solubilization and cellulose mineralization.
\end{abstract}

Keywords: Antifungal Bacillus, Phosphate solubilization, Cellulase activity.

\section{Introduction}

India is an agro-based country and about more than $50 \%$ population is either directly or indirectly dependent on agriculture. Crop yield depends on mainly the soil fertility, control of crop diseases and weather. Indiscriminate use of chemical fertilizers and disease control agents has created many environmental and human health problems. Hence, use of biofertilizers and biological control agents of crop diseases has become an indispensable need of sustainable agriculture. Many species of microorganisms have been isolated from rhizosphere of healthy crop plants and disease suppressive soils and used to prepare biofertilizers and biocontrol formulations. Many rhizosphere microorganisms increase the soil fertility by conducting significant agrochemical processes such as mineralization of complex organic compounds, symbiotic and nonsymbiotic nitrogen fixation, solubilization of phosphorous compounds in soil, etc. [1,2]. These soil microbes are so called 'plant growth promoting microbes' (PGPM). Among the bacteria, species of Pseudomonas and Bacillus have been widely studied and developed as biocontrol agents, some of which also act as biofertilizers $[3,4]$. Phosphorus is the second most important mineral next to nitrogen required for the growth of plants and microorganisms. It constitutes about 3\% cell dry weight mainly in nucleic acids and free nucleotides. However, a major quantity of soil phosphorus exists as organic compounds and insoluble inorganic compounds, such as iron and aluminium phosphates in acidic soils and calcium phosphates in alkaline soil, which are chemically locked for plants $[5,6]$. Microorganisms dissolve this phosphate mainly by producing organic and inorganic acids.

A tremendous amount of agricultural waste is added in soil which is essential to be mineralized by soil microbes. Cellulose, a homopolysaccharide of glucose contributes a major portion. Cellulose digesting microorganisms with the catalytic activity of cellulases are involved in this process. Cellulases is a multienzyme complex consisting of three enzymes- Endo- $\beta$ glucanase/ CMCase (EC 3.2.1.4), Exo- $\beta$ glucanase/ Cellobiohydrolase (EC3.2.1.91) and $\beta$-glucosidase/ Cellobiase [7]. Cellulolytic activity of soil microorganisms is not only significant for biodegradation of cellulosic wastes but also as one of the mechanism of antifungal activity against phytopathogens. The cellulolytic activity of microorganisms is involved in degradation of cell wall of fungal phytopathogens, especially that of 'Oomycetes' [8].

Our aim was to isolate Bacillus species from soil, with antagonistic potential against phytopathogenic Fusarium and Pythium species, phosphate solubilizing ability, and cellulose mineralization potential and to develop a 'all rounder' formulations applicable 
in soil as biocontrol agents as well as biofertilizers.

\section{Materials and Methods}

\section{Isolation and Identification of phytopathogenic fungal cultures-}

Plant pathogenic fungal species were isolated from infected plant material by tissue segment method on PDA supplemented with streptomycin@25mg/lit. The fungal cultures were identified on the basis of cultural characters of one week PDA growth and microscopic characters by mounting with cotton blue. Phytopathogenic Pythium and Fusarium species were selected for further study [9].

\section{Isolation and Identification of Bacillus species-}

150 Bacillus species were isolated from rhizoplane soil samples of healthy crop plants and putatively identified to genus level on the basis of microscopic characters, Gram nature, motility by hanging drop technique and ability to form endospore by Schaeffer-Fulton's method [9].

\section{Screening of antifungal Bacillus isolates-}

Bacillus isolates with good antagonistic potential against Fusarium and Pythium species were selected by Dual culture (Coculture) method, using PDA and PDB [9]. (Sandikar and Awasthi, 2009). Results were recorded in terms of diameter of inhibition zone (I.Z.) on PDA and percent growth inhibition (P.G.I.) in PDB, on 6th day $[9,10]$.

\section{Study of phosphate solubilizing abilities of antifungal Bacillus isolates}

Eight potent antifungal Bacillus isolates obtained by primary and secondary screening were used to test phosphate solubilization ability. The active nutrient broth cultures were individually spot inoculated on Pikovskaya (PVK) agar (Hi-Media M520) plates, three cultures per plate at equidistance and incubated at $280 \mathrm{C}$. Zone of clearance around the growth was observed up to 3 days [2].

\section{Secondary screening of efficient phosphate solubilizers}

The Bacillus isolates showing phosphate solubilization ability in primary screening were individually spot inoculated at the center of PVK plate and incubated at 280C. Diameter of clearance zone was measured successively after $24 \mathrm{~h}$, up to 6 days. The $\mathrm{P}$ solubilization efficiency (PSE) was calculated on 6th day as the ratio of total diameter of clearance zone including bacterial growth $(\mathrm{Z})$ and the colony diameter (C), multiplied by 100. PSE = Z/C $\times 100$ [2,5]. (Gothwal et al., 2006; Sandikar and Awasthi, 2008).

\section{Study of cellulolytic activity of antifungal Bacillus isolates-}

Induction of cellulase activity in cellulose broth-

Cellulases are the extracellular and inducible enzymes. $1 \mathrm{ml}$ active broth culture of each antifungal bacterial isolate was separately inoculated in $100 \mathrm{ml}$ of Carboxyl methyl cellulose (CMC)- Peptone medium (containing g/1 of- Peptone- 10.0 Yeast extract 5.0, $\mathrm{NaCl} 5.0, \mathrm{KH} 2 \mathrm{PO} 45.0$ and Carboxyl methyl cellulose 10.0) in $250 \mathrm{ml}$ Erlenmeyer flasks [8,9]. (Singh et. al., 2001; Sandikar and Awasthi, 2009) and incubated on shaker incubator at $280 \mathrm{C}$ with $120 \mathrm{rpm}$, up to a week.

\section{Detection of cellulolytic activity by DNSA method-}

3,5 dinitro salicylic acid DNSA (yellow) undergoes reduction in hot alkaline solution to 3-amino-5-nitrosalicylic acid (orange-red) in presence of the reducing sugars. The intensity of the coloured product correlates with the amount of reducing sugar produced and the extent of cellulolytic activity [11].

$10 \mathrm{ml}$ of each CMC broth culture was pipetted successively on $3 \mathrm{rd}$, 4th, 5th and 6th day under aseptic conditions and centrifuged at $10,000 \mathrm{rpm}$ for $10 \mathrm{~min}$. $3 \mathrm{ml}$ culture supernatant and $1 \mathrm{ml}$ DNSA reagent was mixed in a test tube. A control (blank) tube containing $1 \mathrm{ml}$ reagent $+3 \mathrm{ml}$ sterile broth was also prepared. The test tubes along with control tubes were covered with marble and placed in boiling waterbath for $5 \mathrm{~min}$. The tubes were cooled to room temperature under tap water and optical density (OD) was read on spectrophotometer at $540 \mathrm{~nm}$, against the blank solution. The amount of reducing sugar produced was determined by using standard graph [8,11]. Cellulose degradation activity was also tested by mixing together all the eight antifungal Bacillus isolates. 


\section{Results}

Table-1 Antifungal activity and Phosphate solubilization ability of Bacillus isolates-

\begin{tabular}{|c|c|c|c|c|c|}
\hline \multirow[t]{2}{*}{ Bacillus isolates } & \multicolumn{2}{|c|}{$\begin{array}{l}\text { Antifungal activity } \\
\text { against Fusarium } \\
\text { species }\end{array}$} & \multicolumn{2}{|c|}{$\begin{array}{l}\text { Antifungal activity } \\
\text { against Pythium } \\
\text { species }\end{array}$} & \multirow[t]{2}{*}{ PSE } \\
\hline & $\begin{array}{l}\text { I Z } \\
\text { mm }\end{array}$ & PGI & I Z & PGI & \\
\hline B. thuringiensis184 & 32 & $\underline{73.63}$ & $\underline{34}$ & 72.08 & 00 \\
\hline B. subtilis208 & $\overline{26}$ & $\overline{63.63}$ & $\overline{30}$ & $\overline{64.16}$ & $\underline{225}$ \\
\hline B. thuringiensis2 11 & 24 & 51.81 & 21 & 51.66 & $\overline{00}$ \\
\hline B. cereus220 & $\underline{30}$ & $\underline{72.18}$ & $\underline{31}$ & $\underline{70.08}$ & $\underline{280}$ \\
\hline B. cereus 228 & $\overline{28}$ & 62.50 & $\overline{28}$ & $\overline{61.66}$ & $\overline{00}$ \\
\hline B. subtilis 252 & 34 & 78.63 & $\underline{35}$ & 76.66 & $\underline{330}$ \\
\hline B. thuringiensis260 & $\overline{22}$ & 50.45 & $\overline{22}$ & $\overline{50.91}$ & $\overline{00}$ \\
\hline B. subtilis 288 & 27 & 51.18 & 30 & 50.00 & 00 \\
\hline
\end{tabular}

I. Z.- Inhibition zone on PDA and P.G.I.- Percent growth inhibition in PDB, on $6^{\text {th }}$ day. PSE- Phosphate solubilization efficiency on $6^{\text {th }}$ day. All values are average of triplicates

Table-2 Cellulase activity of antifungal Bacillus isolates

\begin{tabular}{lcccc}
\hline Bacillus isolates & \multicolumn{4}{c}{ Glucose concentration $\mathbf{( \mu g / \mathbf { m } \mathbf { ) }}$} \\
\cline { 2 - 5 } & 3rd Day & 4th Day & 5th Day & $6^{\text {th }}$ Day \\
\hline B. thuringiensis184 & 00 & 00 & 00 & 00 \\
B. subtilis208 & 00 & 00 & 06 & 08 \\
B. thuringiensis211 & 00 & 00 & 00 & 00 \\
B. cereus220 & 06 & 06 & 07 & 08 \\
B. cereus228 & 00 & 00 & 00 & 00 \\
B. subtilis252 & 20 & 32 & 45 & $\underline{68}$ \\
B. thuringiensis260 & 00 & 00 & 00 & 06 \\
B. subtilis288 & 00 & 00 & 00 & 00 \\
Mixed culture & 34 & 48 & 88 & $\underline{120}$ \\
\hline
\end{tabular}

\section{Discussion:}

\section{Screening and Identification of antifungal Bacillus species}

Eight isolates of Bacillus showing potent antifungal activity (percent growth inhibition > $50 \%$ ) against the phytopathogenic Fusarium and Pythium species obtained by dual culture (Co-culture) method, using PDA and PDB were identified as Bacillus thuringiensis 184, B. subtilis208, B. thuringiensis211, B. cereus220, B. cereus228, B. subtilis252, B. subtilis 260 and B. subtilis 288 .

The antifungal activity of Bacillus isolates was found to vary with species to species as well as with the type of phytopathogen i.e. Fusarium and Pythium. Three isolates i.e. B. thuringiensis184, B. cereus 220 and B. subtilis252 have shown very good antifungal activity i.e. PGI values $>70 \%$ and diameter of inhibition zone $>30 \mathrm{~mm}$. B. subtilis 252 was proved to be the best isolate in this respect with PGI up to $78.63 \%$. All these antifungal Bacillus isolates were used to prepare biocontrol formulations with dried fecal pellets of sheep and goats and proved successful, Sandikar and Awasthi (2009).

\section{Study of Phosphate solubilization ability of Bacillus species}

Among the eight isolates, three isolates i.e. Bacillus subtilis208, B. cereus220 and B. subtilis252 were showed good phosphate solubilization efficiency i.e. 225, 280 and 330 respectively (table-1). It is important to note that, among the three isolates which have shown maximum antifungal activity, two isolates i.e. B. subtilis 252 and B. cereus 220 also shown maximum phosphate solubilization efficiency (PSI) i.e. 330 and 280, respectively. Bacillus subtilis208, B. cereus 220 and B. subtilis252 were proved successful to control Fusarium and Pythium infection and plant growth promotion in pot culture as well as field trials. Bacillus species were found as prominent phosphate solubilizers in rhizosphere of crop plants by Krishnaveni M. S. (2010). Manas et. al., 2012 isolated thermoresistant strains of Bacillus subtilis from cow dung with phosphate solubilization and IAA production abilities. Maheswar and Sathiyavani (2012) isolated efficient phosphate solubilizing Bacillus species from groundnut rhizosphere. 


\section{Cellulolytic activity of Bacillus species}

Among the eight antifungal Bacillus isolates, only one i.e. B. subtilis 252 showed considerable cellulase activity (table-2). The glucose concentration estimated by colourimetric method using the reagent DNSA found to increase successively on $3 \mathrm{rd}$, 4th, 5th and 6 th day as 20,32, 45 and $68 \mu \mathrm{g} / \mathrm{ml}$. A mixed culture of Bacillus however showed enhanced cellulolytic activity i.e. up to 120 on 6th day. Considerable cellulase activity was not observed in case of other antifungal and phosphate solubilizing Bacillus isolates. It may be due to the fact that, cellulose is a complex homopolysaccharide of glucose which is better degraded by combined biochemical activity called 'synergism' of mixed culture. Cellulose degrading bacteria have been isolated from soil, cow dung, gut of termites and compost (Saraswati et al., 2012).

We conclude that, application of bioformulations prepared using Bacillus subtilis208, B. cereus 220 and B. subtilis 252 not only act as biological control of fungal diseases of crops but also act as PGPR to increase soil fertility with respect to phosphate solubilization and cellulose mineralization. The isolate B. subtilis 252 was found to be 'all rounder' in this respect.

\section{References}

Bellows T. S., Fisher T. W., Caltagirone L. E., Dahlsten D. L., Gordh G. and Huffarker C. (2000). Handbook of biological control: Principles and Applications. Academic press, New York.

Campbell R. (1989). Biological control of microbial plant pathogens. Cambridge University Press, New York.

Dal Bello G. M., Monaco C. I. and Simon M. R. (2002). Biological control of seedling blight of wheat caused by Fusarium graminearum with beneficial rhizosphere microorganisms. World J. Microbiol. and Biotech. 18: 627-636.

Gothwal, R. K., Nigam, V. K., Mohan, M. K., Sasmal, D. and P. Ghosh. 2006. Phosphate solubilization by rhizospheric bacterial isolates from economically important desert plants. Indian J. Micribiol. 46(4): 355-361.
Koli P. B., Ghosh J. S. and Govindwar S. P. (2008). Some factors affecting cellulase production from thermophilic Gram negative bacteria. J. Microbial World 10(1):43-47.

Krishnaveni M. S. (2010). Studies on phosphate solubilizing bacteria in rhizosphere and nonrhizosphere soils in different varieties of Foxtail Millet (Setaria italic). International J. of Agriculture and Food Science Technology 1 (1) 2010:23-39.

Maheswar N. U. and Sathiyavani G. (2012). Solubilization of phosphate by Bacillus species from Groundnut (Arachishypogaea L.) rhizosphere. Journal of Chemical and Pharmaceutical Research 4(8):4007-4011.

Manas R. S., Laxminarayan K. and Ramesh C. R. (2012) Phosphorus solubilization by thermotolerant Bacillus subtilis isolated from cow dung. Agricultural Research 1(3):273-279.

Miller G. L. (1959). Dinitrosalicylic acid method for determination of reducing sugar. Analytical Chemistry 31: 426-428.

Sandikar B. M. and Awasthi, R. S. (2008). Phosphate solubilization by antifungal Pseudomonas species isolated from Tomato (Solanum lycopersicum) rhizosphere. J. Microbial World 10 (2):141-146.

Sandikar B. M. and Awasthi, R. S. (2009). Studies on biological control agents against soilborne fungal pathogens of crop plants. Ph. D. Thesis submitted to Swami Ramanand Teerth Marathwada University, Nanded.

Saraswati Bai, M. Ravikumar, D. J. Mukeshkumar, P. Balashanmugam, M. D. Balakumaran and P. T. Kalaichelvan (2012). Cellulase production by Bacillus subtilis isolated from cow dung. Archieves of Applied Science Research 4(1):269-279.

Shrivastav, S., Yadav, K.S. and B.S. Kundu (2004). Prospects of using phosphate-solubilizing Pseudomonas as biofugicide. Indian J. Micribiol. 44(2): 91-94.

Singh J., Batra N. and Sobti R. C. (2001). A highly thermostable, alkaline CMC-ase produced by a newly isolated Bacillus species VG1. World J. Microbiol. Biotech. 17: 761-765.

Wani, P.A. 1980. Studies on phosphate solubilization by microorganisms. J. Maharashtra Agricultural Universities 5:144-147. 